Western University

Scholarship@Western

Brain and Mind Institute Researchers'

Publications

Brain and Mind Institute

$1-18-2021$

\title{
The multiplicity of caregiving burden: a qualitative analysis of families with prolonged disorders of consciousness.
}

\author{
Laura E Gonzalez-Lara \\ Western University, laura.gonzalez@uwo.ca \\ Sarah Munce \\ Jennifer Christian \\ Adrian M Owen \\ Charles Weijer
}

See next page for additional authors

Follow this and additional works at: https://ir.lib.uwo.ca/brainpub

Part of the Neurosciences Commons, and the Psychology Commons

Citation of this paper:

Laura E. Gonzalez-Lara, Sarah Munce, Jennifer Christian, Adrian M. Owen, Charles Weijer \& Fiona Webster (2021) The multiplicity of caregiving burden: a qualitative analysis of families with prolonged disorders of consciousness, Brain Injury, 35:2, 200-208, DOI: 10.1080/02699052.2020.1865565 
Authors

Laura E Gonzalez-Lara, Sarah Munce, Jennifer Christian, Adrian M Owen, Charles Weijer, and Fiona Webster 


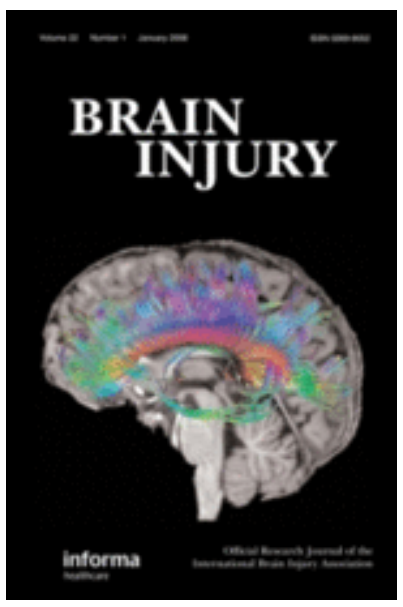

The multiplicity of caregiving burden: A qualitative analysis of families with prolonged disorders of consciousness.

\begin{tabular}{|r|l|}
\hline Journal: & Brain Injury \\
\hline Manuscript ID & TBIN-2019-0463.R1 \\
\hline Manuscript Type: & Original Paper \\
\hline Keywords: & $\begin{array}{l}\text { Caregivers, disorders of consciousness, roles, burden, priorities, } \\
\text { qualitative }\end{array}$ \\
\hline
\end{tabular}

\section{SCHOLARONE}

Manuscripts 


\title{
The multiplicity of caregiving burden: A qualitative analysis of families with prolonged disorders of consciousness.
}

\begin{abstract}
Objective: To understand the multiple and sometimes conflicting roles substitute decision makers (SDMs) of individuals in a vegetative state (VS), minimally conscious state (MCS), or with locked-in syndrome (LIS) perform while caring for a loved one and the competing priorities derived from these roles.

Methods: We conducted semi-structured qualitative interviews using a constructive grounded theory design. Twelve SDMs, who were also family members for 11 patients, were interviewed at two time points (except one) for a total of 21 in-depth interviews.

Results: Participants described that caregiving is often the central role which they identify as their top priority and around which they coordinate and to some extent subordinate their other roles. In addition to caregiving, they participated in a wide variety of roles, which were sometimes in conflict, as they became caregivers for a loved one with chronic and complex needs. SDMs described the caregiver role as complex and intense that lead to physical, emotional, social and economic burdens.

Conclusion: SDMs report high levels of burdens in caring for a person with a prolonged disorder of consciousness. Lack of health system support that recognized the broader context of SDMs lives, including their multiple competing priorities, was a major contributing factor.
\end{abstract}




\section{Introduction}

In recent years, improvements in emergency medicine and critical care have resulted in more patients surviving severe brain injuries $(1,2)$. Some of these patients will have a substantial functional recovery; some will recover, albeit with physical and cognitive impairments; yet another group will remain in vegetative state (VS) or minimally conscious state (MCS), following a period in coma (3). There are no definitive estimates on the world wide prevalence of VS, although it is estimated between 0.2 and 6.1 per 100000 (4). Even though outcomes of patients in a VS have improved over the last twenty years (2), assessment of patients with disorders of consciousness (DoC) remains challenging (5) and the diagnosis relies on subjective interpretation of observed behavior. Patients with DoC are a very diverse population with variable cognitive and behavioral abilities as a result of a wide range of etiologies and comorbidities. The difficulty of the assessment, coupled with inadequate experience and knowledge due, in part, to the relative rarity of these complex conditions, contribute to an alarmingly high rate of misdiagnosis (up to 43\%) in these patient groups (6-8).

These individuals are unable to make their own healthcare decisions, thus a substitute decision maker (SDM), usually a family member, will make these decisions on their behalf. In Ontario, Canada, the SDM is determined through a hierarchy specified in the Health Care Consent Act. Families usually play a central role in the care of patients with DoC as they become SDM, provide care, and endure the emotional strain that accompanies chronic illness and uncertainty about the future (9-12). The burden experienced by caregivers is unique as they are responsible for the patient's well-being yet do not get any direct feedback regarding the person's 
needs or preferences. Yet, we currently understand little about how to best provide support for them in the vital role they play as partners in the delivery of care.

Qualitative studies conducted with families of patients in a VS have often focused on the decision-making process, particularly around end of life care (13-17). Other qualitative studies have explored social and psychological dynamics among family members and how their interpersonal relationships are affected (18-20).

This study is unique in that we sought to understand the burden experienced by families of individuals in a VS or MCS, specifically due to the multiple roles they play during the chronic stage of the injury. Considering that caregiving occurs within the context of complex lives characterized by multiple competing priorities and differing life stages, in this paper we report on how their role as caregivers may conflict with their roles as spouses, parents, employees, and friends.

\section{Methods}

Our team undertook a modified constructivist grounded theory study to better understand the experiences of family members of patients with DoC by focusing on their experiences and how they assigned meaning to these experiences through in-depth interviews. Data collection was aimed at discovering and exploring a participant's experiences and analysis was aimed at making sense of these experiences. Drawing on the principles outlined by Charmaz (21), our data collection and analysis were conducted concurrently, as we continuously reflected on the direction of the research, improvising methodological and analytical approaches throughout the process, and collecting enough data to understand the participants' points of view. Participants were family members acting as the SDM of patients who had participated in functional magnetic 
resonance imaging (fMRI) or electroencephalography (EEG) neuroimaging studies (22-26) on serious brain injury at Western University; able to converse in English; caring for a patient diagnosed as VS, MCS, or with locked-in syndrome (LIS) whose injury had occurred at least one year prior. At the time of the patient's participation in the neuroimaging studies, family members were informed of this qualitative study and their informed consent was obtained if interested (LG). Following informed consent, a time for a face-to-face or telephone interview was arranged when ongoing consent was confirmed. We conducted semi-structured in-depth interviews using interview guides, digitally recording and professionally transcribing the interviews verbatim for analysis. Twelve family members participated in the interviews with a total of 21 in-depth interviews. We interviewed most family members at two time points, before and after receiving neuroimaging assessment results, which are identified as A and B respectively throughout the quotes. There were 11 initial interviews with one having two participants who shared the SDM role. There were 10 interviews in the second time point as one participant chose not to participate. The University of Western Ontario Health Research Ethics Board (REB) and the University of Toronto REB provided ethical approval.

The core research team (LG, SM, CW, FW) coded several transcripts independently and then met as a team 8 times to compare notes and share our interpretation. During these meetings, we developed a coding framework with an experienced research assistant (JC), and then applied it across all transcripts. This process required reflexivity as we challenged and supported each other's views and explored our individual standpoints, including our various disciplinary backgrounds and stages of career (27). Our multi-disciplinary team consisted of a Research Coordinator with a background in Engineering and Medical Biophysics (LG), a Postdoctoral Fellow with Health Services Research expertise (SM), a Research Assistant with qualitative 
research management experience (JC), a qualitative sociologist (FW), a neuroscientist (AMO), and a bioethicist $(\mathrm{CW})$. We drew on our diverse backgrounds in order to help identify our own biases and assumptions. We initially used open coding to organize the data into general concepts. Then we used axial coding to compare relationships between codes (28). The codes were then gathered into groups that shared similar meanings.

\section{Findings}

Twelve family members, eight females and four males, participated in the interviews for a total of 21 in-depth interviews. The diagnosis of the patients, the SDMs' relationship to the patients, time after injury and place of residence of the patient are summarized in Table 1. Most of the interviewed caregivers were spouses or parents. Participants self-identified as the primary caregivers and described in detail the multiple roles they needed to fulfil, the competing priorities between these roles and the resulting burden. In their accounts, participants explained the numerous roles they played by being the SDM, which also meant being the primary caregiver to the patient, as well as advocate within the health care system, financial and/or legal gatekeeper. In addition, most of these participants were also caregivers to other family members and often the primary income-earner in the household. The caregiver role included tasks that could be considered unpaid health care work since the needs of those with a severe brain injury were often not adequately met by the health system. These complex and sometimes conflicting roles appeared to have a significant impact on the participants' physical, social, financial and emotional experiences.

We have organized our findings around the core theme that caregiving is often the central role which the caregiver identifies as their top priority and around which they coordinate and to 
some extent subordinate their other roles. We then describe the inter-related and sometimes conflicting roles of: caregiver as unpaid health care provider, caregiver as advocate, caregiver as a member of a broader family system, caregiver as main financial supporter and gatekeeper, and caregiver as member of the wider community. When these roles were in tension with each other, participants were often unsure which role or responsibility to prioritize.

\section{Caregiving as central role around which others revolve}

Participants often described their primary role as being that of caregiver. They often perceived this as a duty, and described it as a central part of their identity. For example, spouses, who had often been together for decades, explicitly identified their role of caregiver as a duty which they often felt they had no choice but to assume.

'I don't think I have a choice, and not because I need to have a choice: he's my husband and that's the commitment we have, we're going to look after each other... I'm his wife, and he's stuck with me." (P1, A)

Furthermore, in some cases, this perceived duty of caring for someone who is behaviorally nonresponsive and unable to provide feedback regarding their needs or preferences, led the caregivers to sometimes speak without making a clear distinction between themselves and their loved one. For example, some participants often referred in the first-person when narrating events actually related to their family member, identifying with them as a single unit: "you know the dialysis patients, what they go through, and every alternate day there is a dialysis and they have their in-between days doctors' appointment, follow-up and all that. So I've had about, let's say, 424 doctors' appointments since 2004 until now." (P4, A) 
As SDMs, participants took on the responsibility to make many decisions on behalf of the patient. They might share the decision-making responsibility and consult with other family members in certain circumstances depending on how significant they perceived each specific decision to be. For example, they might be comfortable making minor, everyday type of decisions, but perhaps not those that involved a medical procedure.

"So when I say "I make decisions", from the day-to-day perspective, like, you know, does he need an acupuncturist, does he need a massage therapist, but those decisions I make, but if there were other decisions such as, you know, for example at one point we need to decide whether or not the [tracheostomy tube] should be put into him because he had an attack of pneumonia, well, I made that decision but it was with the kids” (P1, A)

The burden of everyday care frequently fell on one person who would usually also make most day-to-day decisions; it appeared that if anything were to happen to the primary caregiver there often would not be anyone else ready/willing to take over. Participants spoke about being overwhelmed by responsibilities and needs to meet, for their loved one with brain injury, as well as other family members and how they felt the burden of all the responsibilities.

“What's happened to me? ... It's so draining doing what I'm doing... one hour of being with him is equivalent to two hours of anybody else's job.... It's a grind, yeah... But somebody has to do it." (P2, A)

The additional and unexpected roles that an SDM suddenly had to take on also affected family dynamics as the primary caregiver might need more emotional support. Even when the role of guardian was shared, it was usually one person who took the lead on the practical aspects of caregiving while another would take on an administrative role (e.g., when the SDMs were parents, it would be common for one to take the lead on dealing with paperwork and payments 
while another one would deal with the hands-on care). For the person providing the everyday care, usually a woman in our sample, this was often an emotionally draining process and this person expressed a need to share their experience and challenges. The emotional burden of hands-on caregiving was not always evident to the person performing the administrative duties, and thus, this person might not be emotionally available to meet the other person's needs. "it's almost like he doesn't want to hear about it. And I say, "Well, this is my job, this is what I do, ”you know? (P2, A)

Most families identified time management as particularly challenging. Managing their daily lives with added appointments was described as stressful and a challenge for their own wellbeing. "Sometimes it is stressful, right, trying to manage a household and... trying to find time to take care of yourself and your health is sometimes stressful also, right? And then you feel guilt when you can't be there with [patient] because of your health... just trying to manage being pulled in a lot of different directions. " $(P 9 b, A)$

\section{Caregiver as unpaid health care provider}

SDMs spent many hours accompanying their loved one to various appointments and recognized that the high needs of their loved one were not always met by the healthcare system. These might include setting up feeding tubes, medications, and sometimes even transfers. Even though most patients live in a hospital or extended care facility setting, with only two families caring for their loved one at home (Table 1), family members would often feel responsible to provide some of the care for their loved one themselves within the facility. "when I'm at the hospital I do all the work, which means [I put this on myself] ... for example, when I'm getting ready to leave for the day I actually put him back into bed 
myself... I get him comfortable... I get him all sorted out, and I put his [tube feeds] on when I'm getting ready to leave... And I make sure that when I walk out of that room that I know my husband's comfortable, okay, because now I need to know." (P7, B)

While participants appreciated the staff could provide some of this care and acknowledged some of the work may have been self-imposed, they also needed to be assured that every aspect of their loved one's care was addressed on a timely fashion. There were other aspects, such as care coordination, which in some cases is provided by a paid employee (e.g., a case manager, social worker, etc.), that would fall on family members. SDMs were able to recognize that the accumulation of the work performed (e.g. coordination of multiple services, specialized transportation, etc.) would be remunerated if done by a professional.

"I reckon if I actually added up my hours and, you know, charged out at 40 bucks an hour... well, actually, probably more. I reckon I'm probably doing a \$60,000 a year job." (P2, A)

\section{Caregiver as advocate}

In addition to coordination and providing hands-on care, a role repeatedly identified by SDMs was being an advocate for their family member with the injury. This role was perceived to enhance the well-being of their loved one, from a medical perspective as well as in relation to ensuring their comfort. At times it also reflected the family member's lack of trust in the adequacy of the medical system to provide an appropriate level of care for their loved one.

"I don't trust them at all. They look at things when the patient is active and whatever, but what about the passive patient? Here's a thing sitting there and it should not deteriorate as the patient is going through this coma situation." $(P 4, B)$ 
The lack of trust was often the result of past medical care experiences, including management of chronic conditions:

"I guess I couldn't really trust somebody anyplace after the experiences we had" (P6, A)

“Anyway, after half an hour she's typing into the computer and she realized that she had made the mistake and it's the wrong address. And then it was returned back to [provincial insurance] and then the number was cancelled" (P2, A)

"Anyway, they wanted to hide the mistake that he did, the radiologist." (P4, B)

Alternatively, some participants described how they were able to build relationships with healthcare providers, who could then also advocate for the patient.

"And finding people that can also be an advocate.... Amazing when you've got people like that on your side. That definitely helps" (P2, B)

Recruiting the additional support, however, depended on the caregiver being comfortable speaking out and identifying professionals who shared their views.

"I did the best I could, and again every step of the way, every day and every time, I did not hesitate to knock at the door of certain people who may provide me some extra mile." (P4, B)

\section{Caregiver as members of broader family systems}

Besides being a caregiver, advocate, and guardian for someone with prolonged DoC, SDMs also needed to perform other roles and meet their other responsibilities such as providing for their household, household chores, parental responsibilities, and spending time with other family members. Participants described how these multiple roles could, at times, be in tension with each other which in some cases resulted in feeling negligent in the care of other family members. 
"That's what [father] and I had to remember... that we were also parents to three other children" (P2, A)

When participants were taking care of spouses, in addition to suddenly becoming caregivers, they also described the burden of taking on family and personal obligations by themselves. Some of these responsibilities might have been previously shared with the patient, for example, parenting. Often the process of mourning, including anticipatory grief and complex grief, impacted significantly on their other roles. They mourn the impending death of the patient and, in some cases, sorrow lasts years of uncertainty with the caregiver unable to resume their own life. For example, many expressed that visiting their loved one was draining as they mourned the loss of a partner as the person they once knew.

"I work, and I have three children and, you know, I'm pretty-much on my own... it's very different when you're alone as opposed [to] when you have a partner" (P5, A)

"I've been informed that it's like the seven (sic) stages of grieving, and you go through this regardless if the person's passed away or that he is in the condition that he's in" (P7, A) In other cases, the family unit might have been very small, consisting only of the person with the injury and the caregiver. Thus, besides becoming caregivers, this also meant they had lost their source of support for everyday life and even their motivation.

"I'm pretty-much on my own, and the only help and support I get is with a female companion that I have that tries to encourage me to eat something, because I'm not eating properly and I'm lacking a lot of motivations to even do anything" (P10, B) Another aspect of the emotional burden that had an impact on the family dynamics was the feeling of powerlessness and, in some cases, even guilt for not being able to prevent the injury or the primary caregiver not wanting to burden other family members. 
"[older brother] had extreme guilt when it first happened... because he's the big brother, he thought he should have been there" (P3, A)

"I don't want to bring any more burden to my son... he does have a lot of stress in his life...

Same with my daughter... I don't want to... bring that to her" (P7, A)

Finally, while participants felt the strain of competing priorities between being a caregiver and fulfilling other family responsibilities, fulfilling other roles could also be rewarding; for example, feeling motivated by taking care of younger children.

“everything, every purpose that I'm doing, everything I'm trying to do is for my children... I'm strong due to my kids." (P5, B)

\section{Caregiver as main financial supporter and gatekeeper}

Participants often provided financial support for their families through paid employment, often as the only remaining income-earner in the case of spouses. These participants had to find balance between financial needs and professional goals, which sometimes would include making difficult decisions.

"It was tough when I lost my job two and a half years ago. It was very tough... that's when I decided I was not going to continue my career, I was going to take a part-time job-just to keep my sanity - but I was going to spend time with him.... now that I've gone back full-time - because I have to pay bills - ... so I have to work." (P1, A)

Trying to accommodate the additional responsibilities as a primary caregiver for patients diagnosed with DoC had sometimes a negative impact on their other roles. For example, SDMs would dedicate a considerable amount of time coordinating care, addressing concerns or at appointments, which meant less time to attend to their other responsibilities. 
"I can't even have a full-time job because these are the problems that I have to deal with, because no one's in the hospital on the weekends, right? So I have to take time off during the week, because after 5:00 there's nobody there either. So these are the challenges you have to deal with, so, you know, it's just not easy to handle things like this." (P1, A)

In addition to matters related to care cost and insurance, there are often financial decisions and procedures that needed to be completed such as legal proceedings, which had financial implications, as a result of the injury. These processes were often difficult to navigate without a certain level of expertise.

"My husband is involved, too, and it was the two of [us] named on the power of attorney as far as taking care of her physical and, you know, administrating her estate and things like that, and her settlement... he was quite trained and versed on legal matters... he did a lot of the financial end of it, you know, just the administration... dealt with the government and stuff like that." (P6, A)

Some patients had been independent adults in the workforce, some with property, and other additional responsibilities such as caring and providing for their own dependents. Depending on the patient's stage of life, it was not always obvious who the long-term SDM and primary caregiver would be. In more than one account, participants described a complicated process to become the SDM. For example, a life partner might be the original SDM and this responsibility might fall to other family members over time. This process could be stressful, painful and conflictual. As one participant described it, this process of changing SDM "was awful, actually it was a nightmare" $(\mathrm{P} 2, \mathrm{~A})$.

The relationship between legal and financial responsibilities in caring for someone with such severe injuries can be complex. For those patients that were already in the workforce and 
financially independent it might have meant that they were the primary income earner in their households. In the case of young adults, even if they were independent, parents often became suddenly and unexpectedly the SDM, which meant they also needed to plan for care in the long term. Furthermore, depending on the cause of the injury, different types of insurance might have been involved with a variety of benefits and paperwork to navigate. SDMs might suddenly find themselves with a need for substantial and costly care while also navigating complex issues such as insurance claims and tax credits.

"Our wills we've got re-written them twice since the accident... We have it set up that there be provision for [patient] in our will, and there's all sorts of tax implications... We also have him signed up for the long-term disability tax credit that's going on. He did receive a settlement from his insurance company as if he had died... brain injury is not covered if you have an injury. If you lose an arm and a leg, you know, you get $\$ 25,000$, or you lose an eye. If you have brain injury it's not covered." (P2, A)

Even when the family situation settled into a routine, it became very difficult when there were other unexpected medical needs among other family members that were complicated by ongoing financial issues related to the patient with prolonged DoC.

"There was a lawsuit [that] went on for seven years... All the while we didn't have enough funds. We were dealing with no-fault insurance, just trying to stay alive... my husband fell down a flight of stairs and had a very severe injury, was in the hospital for five months... he's never totally recovered... he lost his job, he couldn't work anymore and everything, so then we had to start over again." (P6, B) 
To address the financial burden, in some cases, caregivers needed to rely on external financial support from different sources, including family members and government sources; not only for additional services for their loved one, but to meet their own needs.

"I know financially how I coped... with the situation: my kids were very supportive in that situation. You know, bills don't stop, right?" (P4, B)

"I'm on ODSP (Ontario Disability Support Program) right now." (P10, A)

\section{Caregiver as a member of the wider community}

Other social interactions were also affected as participants took on caregiving responsibilities. While participants could express their own need for balance and having personal interests, they found it stressful being aware of their own needs while not having enough time to address them and were concerned about becoming isolated.

"I find sometimes it's hard with outside interests... I do it but I find that sometimes [it] is a strain... But we try and keep it balanced ... it really takes a fine balancing act because you don't want to leave any of them out or turn down too many invitations or you just get left out." (P6, A)

Caregivers described a preference to remain involved in networks outside of their immediate family, including religious communities. Participants often drew on these community resources to meet their needs, to cope with unexpected burdens in caring for their loved ones and fulfilling their own roles, including building strong social networks. For some participants, spiritual faith was an important part of their coping strategies, while also providing the social network from a community with shared beliefs. 
“It's been difficult. I mean, it hasn't come easy, but I think it's my faith, a lot of supportfamily, friends - tremendous support. I think that has helped me in a very big way. But more importantly I think it's been my faith right from day one." (P1, A)

“We've got a very supportive church family and they help with visits... and my husband's been very loving and supportive in this." (P8, A)

Nevertheless, even though many participants had strong support networks, participants recognized that finding help could still be challenging.

“there are very few people available who are flexible in their time. You know, either they're still working, obviously, or they've got other obligations. " $(P 2, A)$

Support networks, flexibility and financial means, for those families who had them, were very valuable to manage the burden of providing care for their loved one.

"the company I work for is pretty flexible, so they understand the situation with [patient]. They're been very supportive" (P3, A)

In another account a participant caring for her son described how her husband's job as a highranking executive at a company, allowed them to move quickly and make living arrangements to be near their son.

In some cases, new support networks were the direct result of their situation, and participants appreciated having the opportunity to rely on others who fully understood their situation and families could relate to each other.

"there's another couple there that have a daughter pretty-well the exact same age as [patient], somewhat the same condition, and when we go in the evenings we'd all of us sit together and chit-chat a bit, nothing too personal and stuff, we just kind of chit-chat, so 
we're in the same... same experiences. And I[have] a couple [of] really, really good friends that are like family" (P3, A)

For those who were able to rely on a strong support network, there seemed to be a change in mind-set that resulted in deliberately looking for positive things. Alternatively, a coping strategy might be carefully planning the timing to receive specific information related to the patient that might be upsetting to avoid the risk of being overwhelmed by it.

'I want to hear the good things but I don't want to hear the bad, right? So sometimes I don't open [the report] ... like, it will be here for a month before I will open it. I mean, I have to be having a good day before I do that... And there's always somebody, like, worse off. I have a look around. She doesn't have cancer. She hasn't, I don't think, suffered like a lot of other people... you just count your blessings where you can find them." (P6, B)

\section{Discussion}

Our participants provided rich descriptions of how caregiving was their main priority around which they organized other roles and responsibilities. They also described in detail multiple aspects of caregiving which could be as varied as providing emotional support, navigating the health care system at the policy level, taking care of financial and legal issues. The process of caregiving differed among participants according to their life stage, their involvement in their communities, and their roles as employees, and members of broader family systems. In addition, not all participants had strong family systems as a source of support available to them.

In the literature, caregiving is often described as a singular activity/role and does not consider the overall and often complex context in which caregiving is performed $(29,30)$. Caregiving has also been largely conceptualized around the patient, not the caregiver themselves. 
Caregiver burden and coping has been largely understood as being about individual psychological states rather than about life stages or contexts. In our study, those families with greater access to material and emotional resources were also more successful in mobilizing coping strategies. This suggests that coping is as much a function of structure as it is of individual competency.

The stories shared by the participants in our study highlighted the many unique features of caring for patients diagnosed with DoC. These caregivers face a chronic state of uncertainty with regard to the trajectory of their loved ones' illness and recovery and the extent of caregiving involved. This is most often compounded by prolonged grief. In addition, these caregivers describe providing care to a loved one without the benefit of feedback. Thus, the care they provide becomes a prioritized responsibility that effects and often mutes how much they are also to contribute to other relationships and other roles in their lives. In other cases, after a brain injury, rehabilitation is expected to improve functional outcomes $(31,32)$, particularly when rehabilitation goals are person-centered and families and unpaid carers are part of the process (33). However, even though outcomes (survival and recovery of consciousness) for patients in VS have improved (2), and patients with moderate to severe brain injuries are likely to benefit from comprehensive rehabilitation (32), recovery for patients in VS remains limited (34). This often leaves caregivers of patients with prolonged DoC in a continual state of loss and grief $(12,35)$. The likelihood for recovery for patients with prolonged DoC is low, families are unable to mourn for a death (36) and yet they grieve over a prolonged time (37). Participants in this study referred to this state as mourning and going through the different stages of grief as family members care for a loved one for prolonged periods of time, often years, with substantial uncertainty not knowing how long they will be caregivers. 
In addition, caregivers often felt a sense of duty, leaving them no choice as to the extent of care they were called to provide, resulting in a sense of loss of control over their lives. Spouses in this study expressed they often experienced a sense of duty concurrently with a confusing sense of mourning similar to what has been previously reported by Hamama-Raz et al. (19). There are few resources available to support caregivers of patients who have survived critical illness, and in the case of patients with prolonged DoC, with considerable needs. Lack of resources and sense of control over life has been reported to be associated with poorer mental health outcomes (38). Caregiving has been previously described as a lonely experience (39) and hopelessness, in particular, has been associated with a higher burden (40). Regardless of the etiology, it has been recognized that providing care for a family member following a severe injury results in emotional, physical, social, and financial strain $(19,41-43)$. In particular, anxiety and depression have a detrimental effect on the mental and physical health of caregivers of VS and MCS patients (44).

Participants in this study described how the caregiver role often included taking on care coordination responsibilities, which is crucial to address gaps in care that exist within the health care system. Care coordination, a role sometimes fulfilled by a case manager or social worker, brought additional responsibilities beyond providing hands-on care, such as appointment scheduling, transportation arrangements, etc., which required a significant time commitment and made balancing competing demands among various roles challenging.

The burden of multiple roles and how family dynamics are disrupted as caregivers balance different responsibilities was previously reported by Giovannetti et al. using a battery of questionnaires with a large cohort study in Europe (46). In our study, participants provided a detailed account through in-depth interviews of their caregiver role as sometimes being 
overwhelming and draining, which made them feel powerless as other family members and friends moved on with their lives. Balancing competing priorities was challenging in part as responsibilities shifted and family dynamics changed following an injury. For instance, in the case of spouses with young families who, in addition to becoming primary caregivers for the partner with brain injury, they simultaneously lost a companion to share parenting responsibilities with. To add to this burden, there may not be emotional support available for children affected by a parent sustaining a traumatic brain injury (TBI) (47) or for the caregiver (48). Family dynamics were also altered in the case of parents caring for an unresponsive child even though decisions would usually be made as a couple. It has been previously reported that caregivers, for critically ill patients and specifically VS/MCS patients tend to be primarily female $(38,46)$. We also found that the routine care in these cases would have distinct divisions with one parent, usually the mother, providing daily, hands-on care (e.g. transport, transfers, feedings) while the other one parent, usually the father, took on administrative duties (e.g., legal, financial issues). This division of duties sometimes led the caregiver to feeling isolated as they perceived a fragmentation of the family in this job division that impacted their personal relationships and overall family dynamics.

As members of the community, participants in our study provided detailed descriptions on their own social networks as a crucial component to managing the burden of caregiving e.g., spending time with their friends or faith communities. They described the need to balance their role as caregivers while also remaining engaged members of their community and expressed concern that if they did not participate in some community activities they would eventually be excluded. A poor social network, in addition to injury severity, was previously identified in a European cohort as a predictor of burden in caregivers of patients with severe TBI. This held 
true, even when the patient had some functional recovery and was no longer considered VS or MCS $(48,50)$. Coping strategies have been recognized as an important aspect to minimize the burden caregivers face (49) and these need to be developed to reduce the psychosocial burden that caregivers of patients with prolonged DoC may experience (51). TBI survivors and caregivers also need mental health services as they are impacted by the increased responsibilities, with competing demands on their time (52), particularly in the case of family members taking care of someone in a VS (53). Relationships within social networks can be particularly affected when the patient lives in a long term facility, which may exacerbate the feeling of isolation for the caregiver who tries to balance personal responsibilities with obligations to his or her family member $(46,54)$.

Oyesanya et al. recently reported on the need to understand more about what families experience, following moderate to severe TBI, so that providers can better meet their needs, and address gaps in expectations and actual services (55). Family members need support regardless of whether they are providing daily care or not. Even when services do exist, families and healthcare professionals may be unaware of them (56). Our findings highlight an urgent need to improve the support family members receive by centering services around them and their multiple and varied experiences and acknowledging the many aspects of caregiving in which they may be engaged. Services should also be tailored to differing life stage and access to resources.

While there were some socioeconomic differences in our sample and the availability of support networks, most participants were also residents of Ontario and had access to provincial healthcare specific to the Canadian context. We acknowledge that this study has some limitations, including the size of our sample being relatively small. By using a sample of 
convenience from those participating in imaging studies our study may be subject to a selection bias as these were participants who had significant knowledge of recent research and the resources to pursue it. The majority of participants were female and caregivers of individuals in a $\underline{\text { VS. Time spent as caregivers varied between subjects, sometimes for decades. The time between }}$ interviews also varied. Nevertheless, we were able to explore the interactions between multiple roles with competing priorities, the burden experienced and coping strategies through in-depth interviews. Our findings converge with those from studies in other countries and with different methodologies in the scope of the burden caregivers face and the need for support in different areas at various times. All participants expressed being overwhelmed at different stages due mostly to limited time to manage the competing priorities from their different roles and limited resources. Social networks were identified as an important part of their coping mechanisms to feel less isolated and able to ask for help. When developing interventions and strategies to improve care, it is important to focus not only on the patient, but on the whole family and their particular contexts for providing care.

\section{Conclusion}

$\underline{\text { SDMs of individuals in a LIS, MCS, or VS play many roles and they report high levels of }}$ burdens in caring for a person with a prolonged DoC. Lack of health system support that $\underline{\text { recognized the broader context of SDMs lives, including their multiple competing priorities, was }}$ a major contributing factor. Their roles included caregiver as unpaid health care provider, caregiver as advocate, caregiver as a member of a broader family system, caregiver as main financial supporter and gatekeeper, and caregiver as member of the wider community. When $\underline{\text { these roles were in tension with each other, participants were often unsure which role or }}$ 
$\underline{\text { responsibility to prioritize. Tailored resources and support for caregivers are necessary as coping }}$ depended on access to material and emotional resources.

\section{References}

1. Fountain DM, Kolias AG, Lecky FE, Bouamra O, Lawrence T, Adams H, et al. Survival Trends After Surgery for Acute Subdural Hematoma in Adults Over a 20-year Period: Ann Surg. 2017 Mar;265(3):590-6.

2. Aidinoff E, Groswasser Z, Bierman U, Gelernter I, Catz A, Gur-Pollack R. Vegetative state outcomes improved over the last two decades. Brain Inj. 2018 Feb 23;32(3):297-302.

3. Eilander HJ, Wijnen VJM, Schouten EJ, Lavrijsen JCM. Ten-to-twelve years after specialized neurorehabilitation of young patients with severe disorders of consciousness: A follow-up study. Brain Inj. 2016 Sep 18;30(11):1302-10.

4. van Erp WS, Lavrijsen JCM, van de Laar FA, Vos PE, Laureys S, Koopmans RTCM. The vegetative state/unresponsive wakefulness syndrome: a systematic review of prevalence studies. Eur J Neurol. 2014 Nov;21(11):1361-8. \{Citation\}

5. Giacino JT, Katz DI, Schiff ND, Whyte J, Ashman EJ, Ashwal S, et al. Comprehensive Systematic Review Update Summary: Disorders of Consciousness. Arch Phys Med Rehabil. 2018 Sep;99(9):1710-9.

6. Childs NL, Mercer WN, Childs HW. Accuracy of diagnosis of persistent vegetative state. Neurology. 1993 Aug;43(8):1465-7.

7. Andrews K, Murphy L, Munday R, Littlewood C. Misdiagnosis of the vegetative state: retrospective study in a rehabilitation unit. BMJ. 1996 Jul 6;313(7048):13-6.

8. Schnakers C, Vanhaudenhuyse A, Giacino J, Ventura M, Boly M, Majerus S, et al. Diagnostic accuracy of the vegetative and minimally conscious state: clinical consensus versus standardized neurobehavioral assessment. BMC Neurol. 2009;9:35.

9. de la Morena MJE, Cruzado JA. Caregivers of patients with disorders of consciousness: coping and prolonged grief. Acta Neurol Scand. 2013 Jun;127(6):413-8.

10. Goudarzi F, Abedi H, Zarea K, Ahmadi F. Multiple Victims: The Result of Caring Patients in Vegetative State. Iran Red Crescent Med J [Internet]. 2015 Jun 23 [cited 2018 Jul 27];17(6). Available from: http://ircmj.com/en/articles/16517.html

11. Cipolletta S, Pasi M, Avesani R. Vita tua, mors mea: The experience of family caregivers of patients in a vegetative state. J Health Psychol. 2016 Jul;21(7):1197-206. 
12. Zaksh Y, Yehene E, Elyashiv M, Altman A. Partially dead, partially separated: establishing the mechanism between ambiguous loss and grief reaction among caregivers of patients with prolonged disorders of consciousness. Clin Rehabil. 2018 Sep 26;026921551880233.

13. Kuehlmeyer K, Borasio GD, Jox RJ. How family caregivers' medical and moral assumptions influence decision making for patients in the vegetative state: a qualitative interview study. J Med Ethics. 2012 Jun;38(6):332-7.

14. Kitzinger J, Kitzinger C. The 'window of opportunity' for death after severe brain injury: family experiences: The 'window of opportunity' for death. Sociol Health Illn. 2013 Sep;35(7):1095-112.

15. Smart CM, Giacino JT. Exploring caregivers' knowledge of and receptivity toward novel diagnostic tests and treatments for persons with post-traumatic disorders of consciousness. NeuroRehabilitation. 2015 Aug 22;37(1):117-30.

16. Kitzinger J, Kitzinger C. Deaths after feeding-tube withdrawal from patients in vegetative and minimally conscious states: A qualitative study of family experience. Palliat Med. 2018 Jul;32(7):1180-8.

17. Span-Sluyter CAMFH, Lavrijsen JCM, van Leeuwen E, Koopmans RTCM. Moral dilemmas and conflicts concerning patients in a vegetative state/unresponsive wakefulness syndrome: shared or non-shared decision making? A qualitative study of the professional perspective in two moral case deliberations. BMC Med Ethics [Internet]. 2018 Dec [cited 2018 Jul 27];19(1). Available from: https://bmcmedethics.biomedcentral.com/articles/10.1186/s12910-018-0247-8

18. Stern JM, Sazbon L, Becker E, Costeff H. Severe behavioural disturbance in families of patients with prolonged coma. Brain Inj. 1988 Sep;2(3):259-62.

19. Hamama-Raz Y, Zabari Y, Buchbinder E. From Hope to Despair, and Back: Being the Wife of a Patient in a Persistent Vegetative State. Qual Health Res. 2013 Feb;23(2):231-40.

20. Noohi E, Peyrovi H, Imani Goghary Z, Kazemi M. Perception of social support among family caregivers of vegetative patients: A qualitative study. Conscious Cogn. 2016 Apr;41:150-8.

21. Charmaz K. Constructionism and the Grounded Theory Method. In: Holstein J, Gubrium J, editors. Handbook of Constructionist Research. New York: The Guilford Press; 2008. p. $397-412$.

22. Beukema S, Gonzalez-Lara LE, Finoia P, Kamau E, Allanson J, Chennu S, et al. A hierarchy of event-related potential markers of auditory processing in disorders of consciousness. NeuroImage Clin. 2016 Feb;12:359-71.

23. Fernández-Espejo D, Rossit S, Owen AM. A Thalamocortical Mechanism for the Absence of Overt Motor Behavior in Covertly Aware Patients. JAMA Neurol. 2015 Dec 1;72(12):1442. 
24. Gibson RM, Chennu S, Fernández-Espejo D, Naci L, Owen AM, Cruse D. Somatosensory attention identifies both overt and covert awareness in disorders of consciousness. Ann Neurol. 2016 Sep;80(3):412-23.

25. Lant ND, Gonzalez-Lara LE, Owen AM, Fernández-Espejo D. Relationship between the anterior forebrain mesocircuit and the default mode network in the structural bases of disorders of consciousness. NeuroImage Clin. 2016;10:27-35.

26. Naci L, Sinai L, Owen AM. Detecting and interpreting conscious experiences in behaviorally non-responsive patients. NeuroImage [Internet]. 2015 Dec [cited 2016 Sep 20]; Available from: http://linkinghub.elsevier.com/retrieve/pii/S1053811915010964

27. Strauss A, Corbin JM. Basics of qualitative research: Grounded theory procedures and techniques. Sage Publications; 1990. 270 p.

28. Strauss AL. Qualitative analysis for social scientists [Internet]. Cambridge: Cambridge University Press; 1987 [cited 2018 Jun 15]. Available from:

http://ebooks.cambridge.org/ref/id/CBO9780511557842

29. Bookman A, Harrington M. Family Caregivers: A Shadow Workforce in the Geriatric Health Care System? J Health Polit Policy Law. 2007 Dec;32(6):1005-41.

30. Sav A, Kendall E, McMillan SS, Kelly F, Whitty JA, King MA, et al. 'You say treatment, I say hard work': treatment burden among people with chronic illness and their carers in Australia. Health Soc Care Community. 2013 May;n/a-n/a.

31. Tuel SM, Presty SK, Meythaler JM, Heinemann AW, Katz RT. Functional improvement in severe head injury after readmission for rehabilitation. Brain Inj. 1992 Aug;6(4):363-72.

32. Greenwald BD, Rigg JL. Neurorehabilitation in traumatic brain injury: does it make a difference? Mt Sinai J Med J Transl Pers Med. 2009 Apr;76(2):182-9.

33. Lloyd A, Bannigan K, Sugavanam T, Freeman J. Experiences of stroke survivors, their families and unpaid carers in goal setting within stroke rehabilitation: a systematic review of qualitative evidence. JBI Database Syst Rev Implement Rep. 2018 Jun;16(6):1418-53.

34. Lee L, Lo YT, See AAQ, Hsieh P-J, James ML, King NKK. Long-term recovery profile of patients with severe disability or in vegetative states following severe primary intracerebral hemorrhage. J Crit Care. 2018 Dec;48:269-75.

35. Giovannetti AM, Černiauskaitè M, Leonardi M, Sattin D, Covelli V. Informal caregivers of patients with disorders of consciousness: Experience of ambiguous loss. Brain Inj. 2015 Mar 21;29(4):473-80.

36. Gray K, Anne Knickman T, Wegner DM. More dead than dead: Perceptions of persons in the persistent vegetative state. Cognition. 2011 Nov;121(2):275-80. 
37. Bastianelli A, Gius E, Cipolletta S. Changes over time in the quality of life, prolonged grief and family strain of family caregivers of patients in vegetative state: A pilot study. $J$ Health Psychol. 2016 May;21(5):844-52.

38. Cameron JI, Chu LM, Matte A, Tomlinson G, Chan L, Thomas C, et al. One-Year Outcomes in Caregivers of Critically Ill Patients. N Engl J Med. 2016 May 12;374(19):1831-41.

39. Prevo L, Hajema K, Linssen E, Kremers S, Crutzen R, Schneider F. Population Characteristics and Needs of Informal Caregivers Associated With the Risk of Perceiving a High Burden: A Cross-Sectional Study. Inq J Health Care Organ Provis Financ. 2018 Jan;55:004695801877557.

40. Romaniello C, Farinelli M, Matera N, Bertoletti E, Pedone V, Northoff G. Anxious attachment style and hopelessness as predictors of burden in caregivers of patients with disorders of consciousness: A pilot study. Brain Inj. 2015 Mar 21;29(4):466-72.

41. Duff D. Family impact and influence following severe traumatic brain injury. Axone Dartm NS. 2006;27(2):9-23.

42. Bayen E, Pradat-Diehl P, Jourdan C, Ghout I, Bosserelle V, Azerad S, et al. Predictors of Informal Care Burden 1 Year After a Severe Traumatic Brain Injury: Results From the PariS-TBI study. J Head Trauma Rehabil. 2013;28(6):408-18.

43. Wittenberg E, Prosser LA. Health as a Family Affair. N Engl J Med. 2016 May 12;374(19):1804-6.

44. Pagani M, Giovannetti AM, Covelli V, Sattin D, Raggi A, Leonardi M. Physical and Mental Health, Anxiety and Depressive Symptoms in Caregivers of Patients in Vegetative State and Minimally Conscious State: Vegetative State and Minimally Conscious State Caregivers' Health. Clin Psychol Psychother. 2014 Sep;21(5):420-6.

45. Quine S, Pierce HP, Lyle DM. Relatives as lay-therapists for the severely head-injured. Brain Inj. 1988 Jun;2(2):139-49.

46. Giovannetti AM, Leonardi M, Pagani M, Sattin D, Raggi A. Burden of caregivers of patients in Vegetative State and Minimally Conscious State. Acta Neurol Scand. 2013 Jan;127(1):10-8.

47. Rohleder P, Lambie J, Hale E. A qualitative study of the emotional coping and support needs of children living with a parent with a brain injury. Brain Inj. 2017 Jan 28;31(2):199-207.

48. Doser K, Norup A. Caregiver burden in Danish family members of patients with severe brain injury: The chronic phase. Brain Inj. 2016 Feb 23;30(3):334-42.

49. Corallo F, Bonanno L, Lo Buono V, De Salvo S, Rifici C, Bramanti A, et al. Coping strategies in caregivers of disorders of consciousness patients. Neurol Sci. 2018 Aug;39(8):1375-81. 
50. Manskow US, Sigurdardottir S, Røe C, Andelic N, Skandsen T, Damsgård E, et al. Factors Affecting Caregiver Burden 1 Year After Severe Traumatic Brain Injury: A Prospective Nationwide Multicenter Study. J Head Trauma Rehabil. 2015;30(6):411-23.

51. Covelli V, Sattin D, Giovannetti AM, Scaratti C, Willems M, Leonardi M. Caregiver's burden in disorders of consciousness: a longitudinal study. Acta Neurol Scand. 2016 Nov;134(5):352-9.

52. Chan J, Parmenter T, Stancliffe R. The impact of traumatic brain injury on the mental health outcomes of individuals and their family carers. Aust E-J Adv Ment Health. 2009 Jan;8(2):155-64.

53. Tresch DD, Sims FH, Duthie EH, Goldstein MD. Patients in a persistent vegetative state attitudes and reactions of family members. J Am Geriatr Soc. 1991 Jan;39(1):17-21.

54. Chiambretto P, Rossi Ferrario S, Zotti AM. Patients in a persistent vegetative state: caregiver attitudes and reactions. Acta Neurol Scand. 2001 Dec;104(6):364-8.

55. Oyesanya T. The experience of patients with ABI and their families during the hospital stay: A systematic review of qualitative literature. Brain Inj. 2017 Jan 28;31(2):151-73.

56. Tverdov AH, S. McClure K, Brownsberger MG, Armstrong SL. Family needs at a post-acute rehabilitation setting and suggestions for supports. Brain Inj. 2016 Feb 23;30(3):324-33. 
Table 1. Participants.

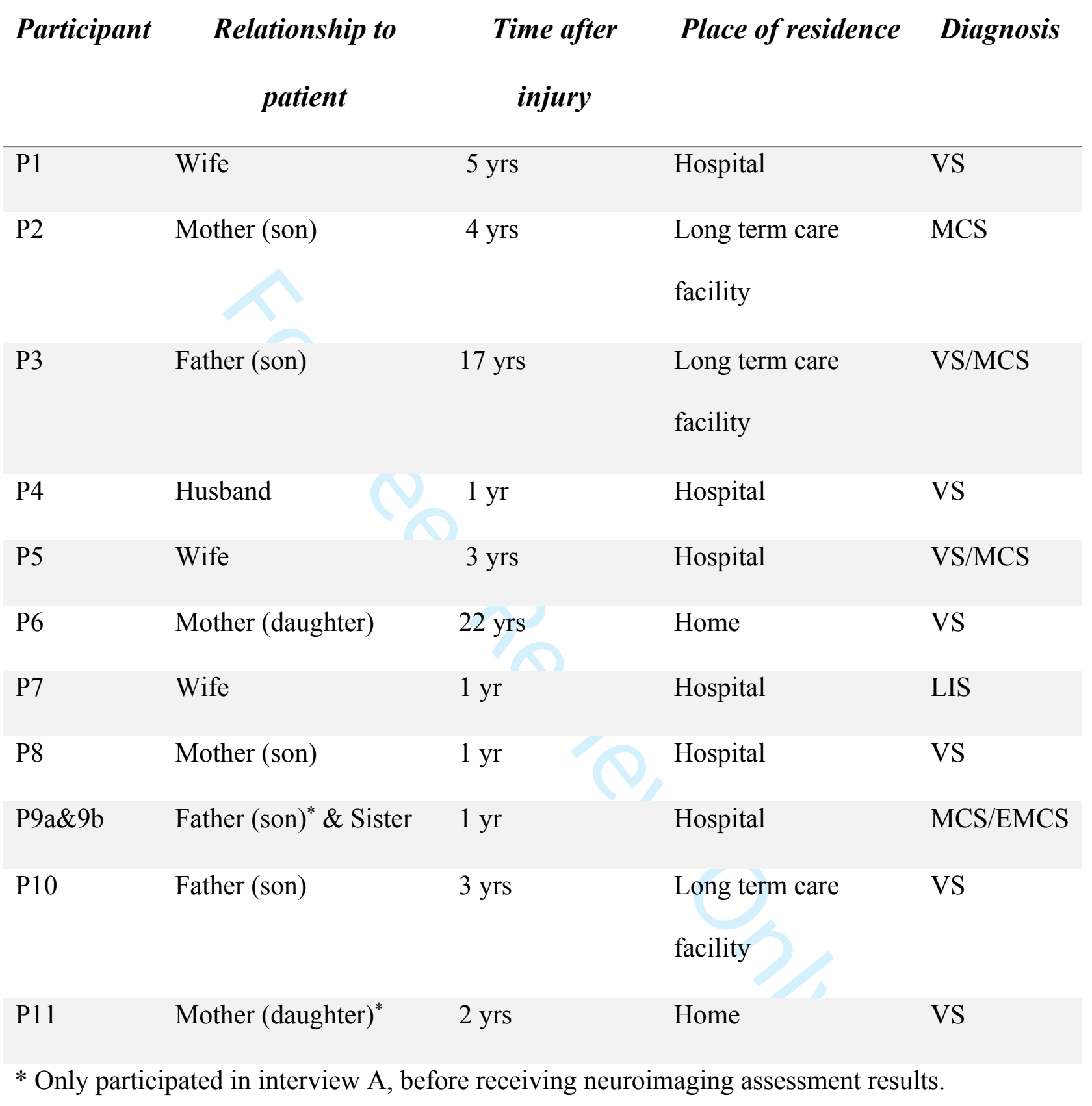


Table 1. Participants.

Participant Relationship to Time after Place of residence Diagnosis

\begin{tabular}{|c|c|c|c|c|}
\hline & patient & injury & & \\
\hline P1 & Wife & $5 \mathrm{yrs}$ & Hospital & VS \\
\hline P2 & Mother (son) & $4 \mathrm{yrs}$ & $\begin{array}{l}\text { Long term care } \\
\text { facility }\end{array}$ & MCS \\
\hline P3 & Father (son) & $17 \mathrm{yrs}$ & $\begin{array}{l}\text { Long term care } \\
\text { facility }\end{array}$ & VS/MCS \\
\hline P4 & Husband & $1 \mathrm{yr}$ & Hospital & VS \\
\hline P5 & Wife & $3 \mathrm{yrs}$ & Hospital & VS/MCS \\
\hline P6 & Mother (daughter) & $22 \mathrm{yrs}$ & Home & VS \\
\hline P7 & Wife & $1 \mathrm{yr}$ & Hospital & LIS \\
\hline P8 & Mother (son) & $1 \mathrm{yr}$ & Hospital & VS \\
\hline P9a\&9b & Father $(\text { son) })^{*} \&$ Sister & $1 \mathrm{yr}$ & Hospital & MCS/EMCS \\
\hline $\mathrm{P} 10$ & Father (son) & $3 \mathrm{yrs}$ & $\begin{array}{l}\text { Long term care } \\
\text { facility }\end{array}$ & VS \\
\hline P11 & Mother (daughter) ${ }^{*}$ & $2 \mathrm{yrs}$ & Home & VS \\
\hline
\end{tabular}

* Only participated in interview A, before receiving neuroimaging assessment results. 